\title{
Karyotypic assignment of Sri Lankan Anopheles culicifacies species B and E does not correlate with cytochrome oxidase subunit I and microsatellite genotypes
}

\author{
Sinnathamby N. Surendran ${ }^{1,2^{*}}$, Nathan Truelove ${ }^{2}$, Devojit K. Sarma ${ }^{2,3}$, Pavilupillai J. Jude ${ }^{1}$, Ranjan Ramasamy ${ }^{4}$,
} Kanapathy Gajapathy ${ }^{1}$, Lalanthika B. S. Peiris ${ }^{5}$, S. H. P. Parakrama Karunaratne ${ }^{6}$ and Catherine Walton ${ }^{2^{*}}$

\begin{abstract}
Background: The identification of species B and E in the Anopheles culicifacies complex in the Indian subcontinent has been based on Y-chromosome karyotype. Since no detectable variations were previously found in DNA markers commonly used for sibling species identification, further molecular characterization using cytochrome oxidase subunit I (COI) and microsatellite markers was carried out on Y-chromosome karyotyped Anopheles culicifacies specie $B$ and E from Unnichchai, Kallady and Ranawarunawa in Sri Lanka.

Findings: $\mathrm{CO}$ / sequence analysis $(n=22)$ revealed the presence of nine unique haplotypes with six in each species. Three haplotypes were shared by both species. The two sibling species had a pairwise $F_{\text {ST }}$ value of $1.338(p<0.05)$ with the number of migrants $(\mathrm{Nm})$ value $<1$. The genetic structure analysis resulted in two genetic clusters not $100 \%$ associated with karyotypes. While none of the species B were incorrectly assigned two were inconclusive. Five out of 26 specimens karyotyped as species E were incorrectly assigned, while further 9 were inconclusive.

Conclusions: The new molecular data support the existence of two genetically different populations of the Culicifacies Complex in Sri Lanka that are not associated with the Y-chromosome karyotype. Detailed analysis with more microsatellite markers and assortative mating experiments are needed to establish the presence of the two genetically distinct populations and relate them to Y-chromosome morphology.
\end{abstract}

Keywords: Anopheles culicifacies, COI, Malaria, Microsatellite, Mosquito vector, Species complex, Sri Lanka, Y-chromosome karyotype

\section{Background}

Anopheles culicifacies Giles sensu lato is the principal vector of malaria in Sri Lanka [1] and a dominant vector elsewhere in Asia [2]. The Anopheles culicifacies species complex in India is comprised of five sibling species A-E [2]. Sibling species E was recently described based on the relationship between Y-chromosome polymorphisms of male offspring and sporozoite infection of mothers in Rameshwaram Island in South India which is in close

\footnotetext{
* Correspondence: noble@jfn.ac.lk; catherine.walton@manchester.ac.uk 'Department of Zoology, Faculty of Science, University of Jaffna, Jaffna 40000, Sri Lanka

${ }^{2}$ Faculty of Life Sciences, University of Manchester, Oxford Road, Manchester M13 9PT, UK

Full list of author information is available at the end of the article
}

proximity to Sri Lanka (Fig. 1) [3]. In India, An. culicifacies sp. B and An. culicifacies sp. E share the same polytene chromosome banding patterns but differ in the position of centromeres in mitotic Y-chromosomes. The latter is acrocentric in species $\mathrm{B}$ and submetacentric in species E [3].

Early polytene chromosome mapping of Sri Lankan An. culicifacies suggested that only species B was present in Sri Lanka [4]. The conundrum that species B is a poor vector of malaria in India $[2,3]$ but the major vector in Sri Lanka was later resolved through Y-chromosome karyotyping Sri Lankan An. culicifacies populations in relation to their vectorial capacity [5]. This indicated that An. culicifacies in Sri Lanka was a mixture of the 


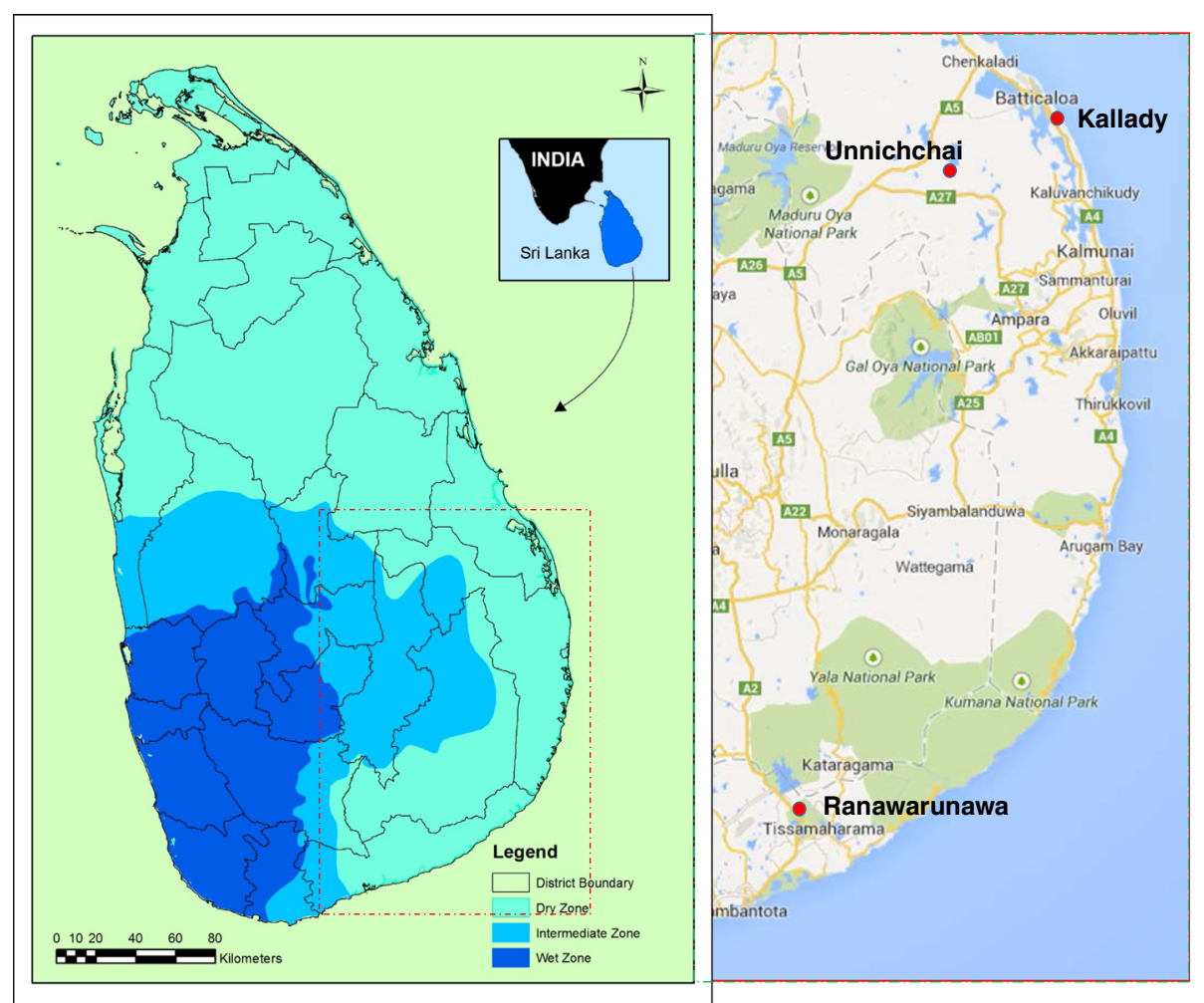

Fig. 1 Mosquito collection sites in Sri Lanka. Map showing the three mosquito collection sites in Sri Lanka, its administrative district boundaries and rainfall zones and the proximity to South India

two putative sibling species $B$ and $E$ based on the presence of the two Y-chromosome karyotypes previously observed in India [5]. Further studies using karyotypically-identified mosquitoes showed that Sri Lankan species E differed from species B in being infectible with Plasmodium falciparum and $P$. vivax and possessing greater resistance to common insecticides [6].

Molecular characterization of the internal transcribed spacer 2 (ITS2) and D3 region of the ribosomal DNA (rDNA), cytochrome oxidase subunit II (COII) and the guanylate cyclase intron failed to differentiate Sri Lankan An. culicifacies sp. B and An. culicifacies sp. E identified by $\mathrm{Y}$-chromosome karyotyping [7]. The present study was therefore carried out to further elucidate the species composition of An. culicifacies s.l. in Sri Lanka using the cytochrome oxidase subunit I (COI) gene, microsatellites and Y-chromosome karyotypes. Specimens with the two different Y-chromosome karyotypes in Sri Lanka are referred to as putative species in this article.

\section{Methods}

\section{Study sites, sample collection and sibling species} identification

Blood-fed anopheline mosquitoes were collected from February 2011 to July 2012 using cattle baited hut collections $(\mathrm{CBHC})$ from three locations found in dry zone of Sri Lanka viz. Unnichchai, Kallady and Ranawarunawa (Fig. 1). Collected mosquitoes were identified at the species level with available morphological key [8]. Blood-fed An. culicifacies females were maintained individually and single female $F_{1}$ progenies were raised as reported previously [5]. Late third and early fourth instar male larvae were used to karyotype Y-chromosomes to identify putative sibling species: acrocentric as species B and submetacentric as species E as described previously [5]. Karyotyped individuals from different $F_{1}$ progenies were used for DNA-based characterisation.

\section{DNA extraction and amplification}

DNA from karyotyped specimens of putative species $B$ and $\mathrm{E}$ was extracted using phenol-chloroform [9]. A portion of the CO1 gene present in mitochondrial DNA was amplified with primers C1-J-1718 and C1-N-2191 [10] as previously reported [9]. The PCR products were purified with the GenElute ${ }^{\mathrm{TM}}$ PCR Clean-UP Kit (SigmaAldrich, USA). Purified PCR products were sequenced in both directions using the Big Dye Terminator V3.1 Cycle Sequencing Kit (Applied Biosystems, USA) on an ABI 3730 automatic DNA sequencer (Applied Biosystems, USA) at the University of Manchester core sequencing facility. Sequence chromatograms were edited manually in 
Geneious 4.8.5 [11] and compared with sequences available from GenBank using BLASTn.

\section{DNA sequence analysis and population genetic structure based on $\mathrm{COI}$ sequences}

Genetic information e.g. number of haplotypes, segregating sites, haplotype diversity and nucleotide diversity was obtained using DnaSP 5.10 [12]. Analysis of molecular variance (AMOVA) [13] and estimation of pairwise $\mathrm{F}_{\mathrm{ST}}$ values for chromosomal forms (species B and E) was performed in Arlequin 3.1 [14] and their significance tested by 1,000 permutations. A statistical parsimony based haplotype network for species B and E populations was created using TCS v1.21 [15].

\section{Microsatellite multiplex, fragment analysis and genotyping}

Thirty nine unrelated individuals from the 3 populations were characterised by the Y-chromosome karyotype and used in the study. Five microsatellite markers capable of amplification from An. culicifacies sp. A and sp. B from India [16] were selected for this study viz. AcAIIB5, ACAVB93, AcAVIB213, AcA 36 and AcA59. Fluorescent-labelled (6-FAM ${ }^{\oplus}, \mathrm{NED}^{\circ}, \mathrm{VIC}^{\oplus}$ and $\mathrm{PET}^{\oplus}$ ) forward primers (Applied Biosystems, UK) and nonlabelled reverse primers (Sigma-Aldrich) were used in a multiplex PCR reaction. Each individual reaction of $5 \mu \mathrm{l}$ consisted of $0.5 \mu \mathrm{l}$ of the 10x primer mix (each primer at $2 \mu \mathrm{M}), 2.5 \mu \mathrm{l}$ of Type-it Multiplex PCR Master Mix (QIAGEN), $1 \mu \mathrm{l}$ of MQ water and $1 \mu \mathrm{l}$ of genomic DNA (10-20 ng). The amplification conditions were; initial denaturation at $95{ }^{\circ} \mathrm{C}$ for $5 \mathrm{~min}$, followed by 26 cycles of $95{ }^{\circ} \mathrm{C}$ for $30 \mathrm{~s}, 57{ }^{\circ} \mathrm{C}$ for $120 \mathrm{~s}$, and $72{ }^{\circ} \mathrm{C}$ for $30 \mathrm{~s}$. This was followed by final extension at $60{ }^{\circ} \mathrm{C}$ for $30 \mathrm{~min}$. The PCR product was diluted with $5 \mu \mathrm{MQ}$ water and $0.5 \mu \mathrm{l}$ of this was mixed with $9.5 \mu \mathrm{l}$ of a mix consisting $\mathrm{Hi}-\mathrm{Di}$ Formamide $^{\oplus}$ (Applied Biosystem) and GeneScan - 500 LIZ Size Standard (37:1) prior to genotyping on an ABI 3730 automatic DNA sequencer using GeneMapper ${ }^{\circledR}$ v.3.7software (Applied Biosystems, USA).

\section{Microsatellite data analysis}

Genetic structure of An. culicifacies s.l. was examined as a single population and two chromosomal forms using the program STRUCTURE version 2.3.4 [17], with a burn in of 100,000 for each value of $\mathrm{K}$ from 1 to 5 . In order to quantify the amount of variation of the likelihood for each $\mathrm{K}$, a data set of 20 runs were carried out. The appropriate $\mathrm{K}$ value was determined using STRUCTURE HARVEST online [18]. The effective migration rate $(\mathrm{Nm})$ between the putative species was estimated using GENEPOP version 4.2 [19].

\section{Findings}

Thirty nine isofemale larval progenies were karyotyped and 13 were identified putative An. culicifacies sp B and 26 as sp E. All mosquitoes collected from Unnichchai were identified as An. culicifacies sp. B and all from Kallady and Ranawarunawa as An. culicifacies sp. E.

\section{Genetic structure inferred from $\mathrm{COI}$ sequences}

Twelve putative species B and 10 putative species E were initially amplified and sequenced for COI. After trimming sequences to the same length, a dataset $449 \mathrm{bp}$ in length, was used for analysis. The two putative species had a pairwise $\mathrm{F}_{\mathrm{ST}}$ value of $0.1338(p<0.05)$. However the $\mathrm{F}_{\mathrm{ST}}$ value of $0.139(p<0.05)$ found to be greater between the geographically more distant An. culicifacies sp. B of Unnichchai and An. culicifacies sp. E of Ranawarunawa. There were nine haplotypes altogether (the corresponding haplotype sequences are deposited in GenBank accession numbers KJ 010890 - KJ 010898) and the statistical parsimony haplotype network (Fig. 2) shows that three of these haplotypes ( $\mathrm{H} 1, \mathrm{H} 4$ and $\mathrm{H} 6$ ) were shared by both putative species without any clustering associated with chromosomal forms.

\section{Genetic structure inferred from microsatellites}

Genetic structure analysis supported by STRUCTURE clustering algorithm analysis followed by STRUCTURE HARVEST revealed two genetic clusters in all analysis viz. as single population and two chromosomal forms (Fig. 3). When considered as a single population, the samples clearly grouped into two clusters (Fig. 3a) while as two chromosomal forms, although the samples were clustered into two, 11 out of 13 chromosomal form B and 12 out of 26 chromosomal form $\mathrm{E}$ were assigned correctly. While none of the An. culicifacies sp. B were incorrectly assigned two were inconclusive. In An. culicifacies sp. E, five out of 26 were incorrectly assigned while nine were inconclusive (Table 1; Fig. 3b). The number of migrants $(\mathrm{Nm})$ value was $<1$ (0.55242).

\section{Discussion}

This is the first attempt to use microsatellite markers to characterize An. culicifacies s.l. populations in Sri Lanka. The COI sequence analysis of the two chromosomal forms resulted in three shared haplotypes suggests that the two putative species An. culicifacies sp. B and $A n$. culicifacies sp. E in Sri Lanka are not reproductively isolated. However, the $\mathrm{F}_{\mathrm{ST}}$ value of $0.1338(p<0.05)$ may be an indication that the populations of putative $A n$. culicifacies sp. B and An. culicifacies sp. E have genetic differences. Because the distance between Unnichchai and Ranawarunawa is $\sim 165 \mathrm{~km}$, a somewhat higher $\mathrm{F}_{\mathrm{ST}}$ value for An. culicifacies sp. B of Unnichchai and $A n$. culicifacies sp. E of Ranawarunawa of $0.139(p<0.05)$, is 


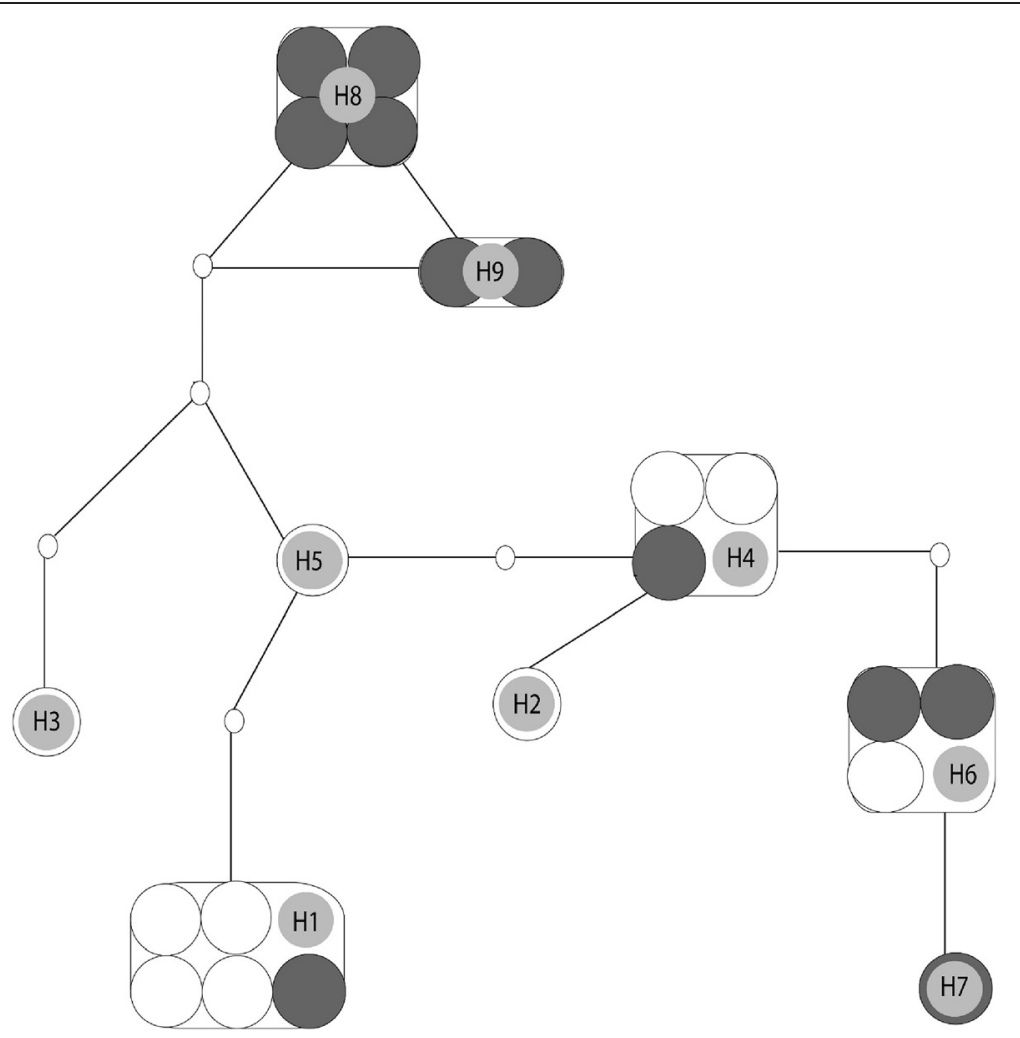

Fig. 2 Haplotype network of $\mathrm{COI}$ of the An. culicifacies s.l. populations. The network is composed of sibling species B (black large circles) and E (white large circles). Large circles indicate individual sequences and the haplotype numbers are shown as $\mathrm{H}$ series. Small empty circles represent missing hypothetical haplotypes

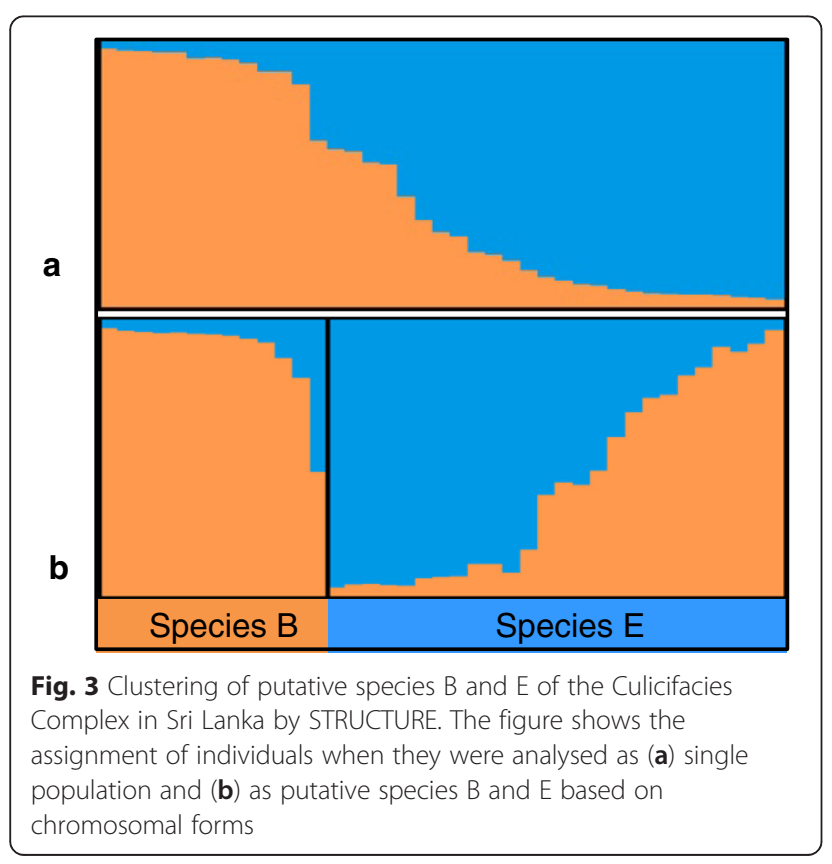

an indication that geographical distance and barriers within Sri Lanka may have a role in genetic variation. Geographical influence is also supported by the presence of only one of the putative species at each of the three locations viz. An. culicifacies sp. B in Unnichchai and An. culicifacies sp. E in Kallady and Ranawarunawa. The observed low $\mathrm{Nm}$ value $(<1)$ is however consistent with there being gene flow between the two putative sibling species.

The microsatellite analysis revealed the presence of two genetically distinct populations within the Culicifacies Complex in Sri Lanka but that these taxa are not delineated by Y-chromosome dimorphism. Of 39 karyotyped individuals, 11 of both An. culicifacies sp. B and An. culicifacies sp. E were inconclusive while 5 individuals of An. culicifacies sp. E were incorrectly assigned. This indicates that the detected population structuring is not associated with Y-chromosome assignment to putative species $B$ and $E$.

It was suggested based on a study that correlated genetic structure of chromosomal forms of shrews (Sorex araneus) based on microsatellite data that karyotypic differences played a minor role in structuring the population relative to others such as geographic or historical factors [20]. Structural variations in the sex 
Table 1 Assignment of karyotypically identified species B and E of the Anopheles culicifacies Complex based on microsatellites

\begin{tabular}{llll}
\hline Species assignment by karyotype & $\begin{array}{l}\text { Number of individuals } \\
\text { not assigned clearly }\end{array}$ & $\begin{array}{l}\text { Number of individuals } \\
\text { assigned to sp. } B(q>0.8)\end{array}$ & $\begin{array}{l}\text { Number of individuals } \\
\text { assigned to sp. } E(p>0.8)\end{array}$ \\
\hline B & 2 & 11 & 0 \\
E & 9 & 5 & 12 \\
\hline
\end{tabular}

chromosomes are not associated with reproductive isolation [21]. The existence of An. culicifacies sp. E in India was based solely on Y-chromosome dimorphism associating with vector potentiality. Since the mothers of acrocentric Y-chromosome progeny were not infected with malaria parasites, they were designated as $A n$. culicifacies sp. B and the infected mothers of males with metacentric Y-chromosomes as An. culicifacies sp. E [3]. The observed Y-chromosome dimorphisms [5] associated with differential vector potentiality [6] suggested that the Culicifacies Complex in Sri Lanka too is composed of two analogous sibling species viz. An. culicifacies sp. B (non vector) and An. culicifacies sp. E (vector), although assortative mating could not be tested.

At present no single technique is available to directly identify all five sibling species in the Culicifacies Complex in the Indian subcontinent. A recent study carried out in India confirmed the previous report on the lack of molecular differentiation between putative sibling species B and E of the Culicifacies Complex in Sri Lanka [7] and revealed that a mtDNA-COII based diagnostic assay [22] that was earlier reported to distinguish all five sibling species (A-E) in the Culicifacies Complex could not be used universally to distinguish all five members including An. culicifacies sp. B and An. culicifacies sp. E [23]. This study further suggests that the Culicifacies Complex is composed of only two distinct species $A n$. culicifacies sp. A and An. culicifacies sp. B from which other members of Culicifacies Complex (species C, D and E) have recently diverged but not yet become reproductively isolated [23].

All the presently available evidence including phenotypic differences (e.g. infectivity with malaria parasites and insecticide resistance) and molecular data are compatible with a suggestion that divergence of An. culicifacies sp. B and An. culicifacies sp. E is a very recent event that may be part of ongoing speciation process with little molecular difference between the two forms. Therefore it is important to examine additional microsatellite markers and the possibility that acrocentricity or metacentricity in the Y-chromosome karyotype of An. culicifacies s.l., as commonly determined in the laboratory, may not be a robust marker for differentiating putative sibling species An. culicifacies sp. B from An. culicifacies sp. E (or non-malaria vector from malaria vector respectively) in Sri Lanka.
The presence of Y-chromosome dimorphism in vector sibling An. culicifacies sp. C of the Culicifacies Complex in India has already been reported [24]. However association of these two karyotypes with parasite transmission or their possible status as two sibling species is presently unknown.

Reproductive isolation in An. gambiae s. s. populations correlates with molecular variations rather than chromosomal differences [25]. It is possible that An. culicifcaies s.l. in Sri Lanka is composed of different populations with different biological and genetic properties but not wholly reproductively isolated. It is important to analyze An. culicifacies s.l. samples from other locations to establish an integral population genetic structure for Sri Lanka and compare this with that of South Indian $A n$. culicifacies. Experiments to assess the capacity for mating and production of viable offspring between the two putative species identified through the two Ychromosome karyotypes in Sri Lanka and in India are also necessary.

\section{Competing interests}

The authors declare that they have no competing interests.

\section{Authors' contributions}

SNS, CW and RR designed the study. PJJ, KG, SHPPK and LBSP did field collections and identification. SNS, DKS and NT did laboratory studies. SNS, NT and CW did data analysis. SNS, CW and RR wrote the manuscript. All authors read and approved the final manuscript.

\section{Acknowledgements}

The authors wish to acknowledge the following: The National Science Foundation of Sri Lanka (RG/BT/2011/04) and The Commonwealth Commission of United Kingdom (Academic Staff Fellowship Awarded to the first author) for financial assistance; The Director, National Anti-Malaria Campaign, Sri Lanka for permission to collect mosquitoes and members of the Entomology Team of the Anti-Malaria Campaign of the district of Hambantota for field assistance.

\section{Author details}

${ }^{1}$ Department of Zoology, Faculty of Science, University of Jaffna, Jaffna 40000, Sri Lanka. ${ }^{2}$ Faculty of Life Sciences, University of Manchester, Oxford Road, Manchester M13 9PT, UK. ${ }^{3}$ Regional Medical Research Centre, NE region (ICMR), Dibrugarh 786001Assam, India. ${ }^{4}$ Faculty of Science and Technology, Anglia Ruskin University, Cambridge CB1 1PT, UK. ${ }^{5}$ Regional Office, Anti Malaria Campaign, Hambantota 82000, Sri Lanka. ${ }^{6}$ Department of Zoology, Faculty of Science, University of Peradeniya, Peradeniya 20400, Sri Lanka.

Received: 22 April 2015 Accepted: 8 June 2015

Published online: 14 June 2015

\section{References}

1. Surendran SN, Ramasamy R. The Anopheles culicifacies and An. subpictus complexes in Sri Lanka and their implications for malaria control in the country. Trop Med Health. 2010;38(1):1-10. 
2. Sinka ME, Bangs MJ, Manguin S, Chareonviriyaphap T, Patil AP, Temperley $\mathrm{WH}$, et al. The dominant Anopheles vectors of human malaria in the AsiaPacific region: occurrence data, distribution maps and bionomic précis. Parasit Vectors. 2011;4:89. doi:10.1186/1756-3305-4-89.

3. Kar I, Subbarao SK, Eapen A, Ravindran J, Satyanarayana TS, Raghavendra K, et al. Evidence for a new vector species $\mathrm{E}$ within the Anopheles culicifacies complex (Diptera: Culicidae). J Med Entomol. 1999;36:595-600.

4. Abhayawardana TA, Dilrukshi RKC, Wijesuriya SRE. Cytotaxonomic examination for sibling species in the taxon Anopheles culicifacies Giles in Sri Lanka. Indian J Malariol. 1996;33:74-80.

5. Surendran SN, Abhayawardana TA, de SDilva BGDNK, Ramasamy MS, Ramasamy R. Anopheles culicifacies Y-chromosome dimorphism indicates the presence of sibling species ( $B$ and $E$ ) with different malaria vector potential in Sri Lanka. Med Vet Entomol. 2000;14:437-40.

6. Surendran SN, Ramasamy MS, de Silva BGDNK, Ramasamy R. Anopheles culicifacies sibling species B and E in Sri Lanka differ in longevity and in their susceptibility to malaria parasite infection and common insecticide. Med Vet Entomol. 2006;20(1):153-6.

7. Surendran SN, Hawkes NJ, Steven A, Hemingway J, Ramasamy R. Molecular studies of Anopheles culicifacies (Diptera: Culicidae) in Sri Lanka: sibling species B and E show sequence identity at multiple loci. Eur J Entomol. 2006;103:233-7.

8. Amerasinghe FP. A guide to the identification of the anopheline mosquitoes (Diptera: Culicidae) of Sri Lanka -I Adult females. Cey J Sci (Biological Science). 1990;21:1-16.

9. Surendran SN, Sarma DK, Jude PJ, Kemppainen P, Kanthakumaran N, Gajapathy K, Peiris LBS, Ramasamy R, Walton C: Molecular characterization and identification of members of the Anopheles subpictus complex in Sri Lanka. Malar J, 12: 304 doi: 10.1186/1475-2875-12-304.

10. Simon C, Frati F, Beckenbach A, Crepsi B, Liu H, Flook P. Evolution, weighting and phylogenetic utility of mitochondrial gene sequences and a compilation of conserved polymerase chain reaction primers. Ann Entomol Soc Am. 1994;87:651-701.

11. Drummond AJ, Ashton B, Buxton S, Cheung M, Cooper A, Heled J, Kearse M, Moir R, Stones-Havas S, Sturrock S, Thierer T, Wilson A: Geneious version 4.8.5. http://www.geneious.com.

12. Librado P, Rozas J. DnaSP v5: A software for comprehensive analysis of DNA polymorphism data. Bioinformatics. 2009;25:1451-2.

13. Excoffier L, Smouse PE, Quattro JM. Analysis of molecular variance inferred for metric distances among DNA haplotypes: application to human mitochondrial DNA restriction data. Genetics. 1992;131:479-91.

14. Excoffier L, Laval G, Schneider S. Arlequin (ver 3.0): An integrated software package for population genetics data analysis. Evol Bioinform Online. 2005;1:47-50.

15. Clement MD, Posada D, Crandall KA. TCS: a computer programme to estimate gene genealogies. Mol Ecol. 2000;9:1657-9.

16. Sunil S, Raghavendra K, Singh OP, Malhotra P, Huang $Y$, Zheng $L$, et al. Isolation and characterization of microsatellite markers from malaria vector, Anopheles culicifacies. Mol Ecol Notes. 2004;4:440-2.

17. Pritchard JK, Stephens M, Donnelly P. Inference of population structure using multilocus genotypes. Genetics. 2000;155:945-59.

18. Earl DA, von Holdt BM. STRUCTURE HARVESTER: a website and programme for visualizing STRUCTURE output and implementing Evanno method. Conserv Genet Resour. 2012;4(2):359-61. doi:10.1007/s12686-011-9548-7.

19. Rousset F. Genepop'007: a complete reimplementation of the Genepop software for Windows and Linux. Mol Ecol Resour. 2008;8:103-6.

20. Paetkau D, Calvert W, Stirling I, Strobeck C. Microsatellite analysis of population structure in Canadian polar bears. Mol Ecol. 1995;4:347-54.

21. Choochote W. Evidence to support karyotypic variation of the mosquito Anopheles peditaeniatus in Thailand. J Insect Sci. 2011;11:10. doi.org/10.1673/ 031.011.0110.

22. Goswami G, Singh OP, Nanda N, Raghavendra K, Gakhar SK, Subbarao SK Identification of all members of the Anopheles culicifacies complex using allele-specific polymerase chain reaction assays. Am J Trop Med Hyg. 2006;75(3):454-60

23. Manonmani AM, Mathivanan AK, Sadanandane C, Jambulingam P. Evaluation of the mtDNA-COll region based species specific assay for identifying members of the Anopheles culicifacies complex. J Arthropod-Borne Dis. 2013;7(2):154-63.
24. Adak T, Sarbjit K, Wattal S, Nanda N, Sharma VP. Y-chromosome polymorphism in species B and C of the Anopheles culicifacies complex. J Am Mosq Control Assoc. 1997;13:379-83.

25. Della Torre A, Fanello C, Akogbeto M, Dossou-Yovo J, Favia G, Petrarca V et al. Molecular evidence of incipient speciation within Anopheles gambiae s.s. in West Africa. Insect Mol Biol. 2001;10:9-18.

\section{Submit your next manuscript to BioMed Central and take full advantage of:}

- Convenient online submission

- Thorough peer review

- No space constraints or color figure charges

- Immediate publication on acceptance

- Inclusion in PubMed, CAS, Scopus and Google Scholar

- Research which is freely available for redistribution

Submit your manuscript at www.biomedcentral.com/submit
C BioMed Central 